\title{
Influence of aging on Doppler echocardiographic indices of left ventricular diastolic function
}

\author{
PAOLO SPIRITO, BARRY J MARON
}

From the Echocardiography Laboratory, National Heart, Lung, and Blood Institute, National Institutes of Health, Bethesda, Maryland, USA

SUMMARY The influence of age on six Doppler echocardiographic indices of left ventricular diastolic function was assessed in 86 normal volunteers aged from 20 to 74 years (mean 36). Five of 6 the six indices showed a linear relation with age. Duration of isovolumic relaxation and maximal $s$ late diastolic (atrial) flow velocity increased significantly with age $(r=0.34$ and $r=0.69$, N respectively). Conversely, maximal early diastolic flow velocity, the rate of decrease (deceleration) ? of flow velocity in early diastole, and the ratio between maximal early and late diastolic flow velocities decreased significantly with age $(r=-0.30, r=-0.40$, and $r=-0.63$, respectively). Duration of the early diastolic flow velocity peak did not show a linear relation with age $(r=0.04)$. Comparison of Doppler indices of diastolic performance among different age groups (20 to $29 \vec{\circ}$

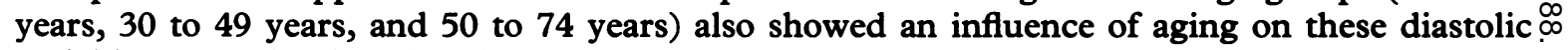
variables. Isovolumic relaxation was significantly longer in older subjects than in either the $O$ intermediate or the younger age groups. In addition, both the rate of decrease of flow velocity in early diastole and the ratio between maximal early and late diastolic flow velocities were $\bar{\partial}$ significantly reduced in older subjects. Multivariate linear regression analysis showed that after $\frac{0}{0}$ adjustment for left ventricular wall thickness and cavity dimension, percentage systolic shortening, $\stackrel{\infty}{\circ}$ and heart rate, age continued to correlate significantly with most Doppler indices of diastolic $\overrightarrow{\vec{O}}$ function.

The isovolumic relaxation phase and the early and late filling phases of diastole, as assessed by Doppler echocardiography, are importantly and independently affected by aging. Hence the effects of age should be taken into account when the normal limits for Doppler indices of left ventricular diastolic function are defined.

Recently, Doppler echocardiography has been used to assess left ventricular diastolic function in patients with various cardiac diseases and in normal subjects. ${ }^{1-10}$ Indices of diastolic function obtained by Doppler echocardiography have also been shown to correlate well with those measured by either contrast angiography ${ }^{4}$ or radionuclide angiography. ${ }^{510}$ Some determinants of left ventricular filling assessed by Doppler, however, seem to be affected by age. ${ }^{171}$ Such age related changes in left ventricular filling patterns may be important in defining normal values for Doppler indices of diastolic function.

To achieve a better understanding of the effects of

Requests for reprints to Dr Paolo Spirito, Divisione di Cardiologia, Ente Ospedaliero Ospedali Galliera, Via Volta 8, 16128 Genoa, Italy.

Accepted for publication 18 December 1987 aging on Doppler indices of left ventricular diastolic performance we obtained Doppler echocardiogra- 0 phic measurements of isovolumic relaxation and of the early and late filling phases of diastole in a group of healthy volunteers with a wide range of ages.

\section{Subjects and methods}

STUDY POPULATION
We measured Doppler echocardiographic indices of

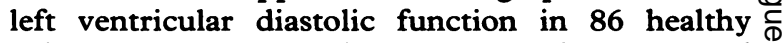
volunteers (48 men and 38 women) who were aged $\stackrel{?}{?}$ from 20 to 74 years (mean 36). None had a clinical 0 history of cardiac disease or of systemic hypertension $\vec{P}$ and all had a normal $M$ mode and cross sectional $\stackrel{\square}{\square}$ echocardiogram. The data were examined by linear $\stackrel{\mathbb{Q}}{\mathbb{Q}}$ regression analysis. In addition, we compared Doppler diastolic measurements among three age 
groups: (a) 35 subjects aged from 20 to 29 years (mean 22); (b) 33 aged 30 to 49 years (mean 40); and (c) 18 aged 50 to 74 years (mean 57). Doppler indices of left ventricular diastolic flow velocity in men and women (within each age group) were also compared to determine whether sex differences independently influence diastolic performance.

\section{DOPPLER ECHOCARDIOGRAPHY}

We used an Advanced Technology Laboratory Mark 500 ultrasound system for the Doppler echocardiographic studies. This instrument combines a pulsed Doppler flow analyser with a $3.0 \mathrm{MHz}$, on line, two dimensional wide angle $\left(90^{\circ}\right)$ mechanical sector scanner. The system has a movable cursor and the Doppler sample volume can be positioned anywhere in the cross sectional sector plane and at any depth up to $17 \mathrm{~cm}$. The depths we used to obtain the left ventricular diastolic flow velocity profiles ranged from 9 to $13 \mathrm{~cm}$. The dimensions of the sample volume at these depths were $5-7 \mathrm{~mm}$ (length) $\times$ $1.5 \mathrm{~mm}$ (diameter) $\times 1.5 \mathrm{~mm}$ (depth).

Doppler output was available as an audio signal and as a spectral display of the flow velocity profile.

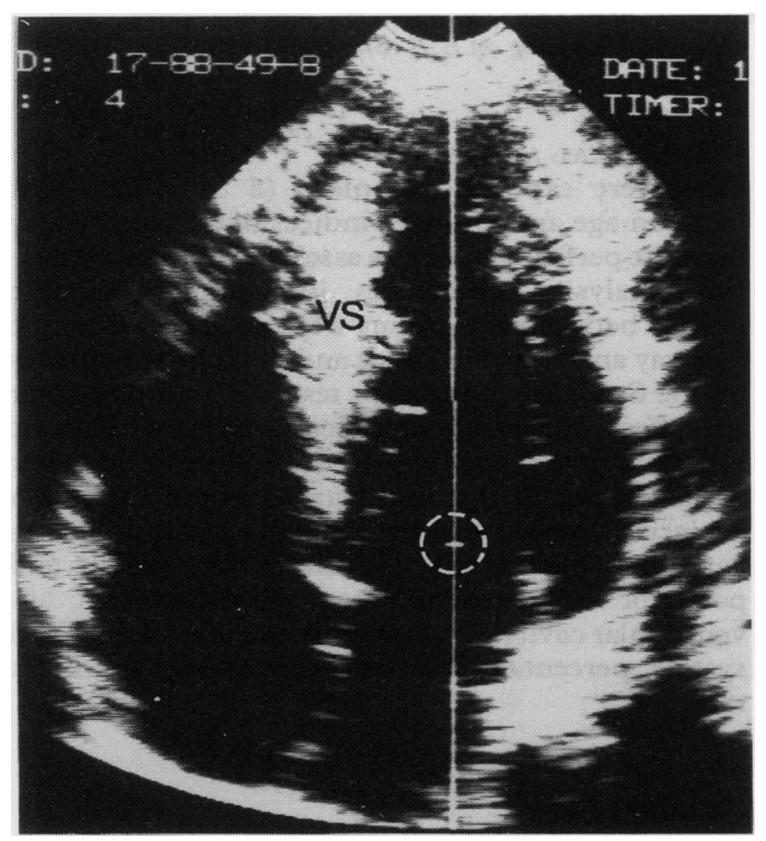

Fig 1 Stop frame cross sectional echocardiogram showing the position of the Doppler sample volume (enclosed within the broken circle) that was used for left ventricular diastolic flow velocity waveforms. The sample volume is positioned within the inflow area of the left ventricle. VS, ventricular septum. Reproduced with permission of American College of Cardiology from Spirito et al..$^{5}$
The spectral display was obtained by electronic fastFourier transform analysis of the Doppler signal, with sampling at $10 \mathrm{~ms}$ intervals and division of the signal into 128 frequency bins. The flow velocity profile was displayed as a waveform composed of small individual grey and black blocks that appeared simultaneously on a monitor with the lead II electrocardiogram and a phonocardiogram and was recorded on a strip-chart recorder at a paper speed of $100 \mathrm{~mm} / \mathrm{second}$. The setting of the instrument was adjusted to use the lowest possible filters.

The Doppler recordings were obtained during quiet respiration with the subject in a lateral recumbent position. The transducer was positioned at or slightly to the left of the cardiac apical impulse, and was oriented to obtain an apical four chamber view of the heart that gave good visualisation of the left ventricular cavity and maximal excursion of the mitral valve leaflets. The cursor line was directed through a plane traversing the left ventricle from the apex to the mitral valve annulus. The angle between the presumed direction of the diastolic blood flow and the orientation of the ultrasound beam (cursor) was estimated to be zero or $<20^{\circ}$ in each subject. The sample volume was placed in the inflow area of the left ventricle, about $1 \mathrm{~cm}$ from the mitral valve annulus (fig 1), and the position of the sample along the cursor line was adjusted until the maximal diastolic flow velocities were recorded and the graphic quality of the Doppler waveform was most clearly defined.

QUANTITATIVE ASSESSMENT OF DIASTOLIC FLOW VELOCITY WAVEFORM

In each subject we chose for analysis three cardiac cycles with the most clearly defined flow velocity waveform and the steepest descent of flow velocity in early diastole. Left ventricular diastolic flow velocity waveforms from the three cardiac cycles were measured and the values were averaged for (figure 2a) (a) time interval from the first positive deflection of the aortic closing component of the second heart sound to the onset of the diastolic flow velocity waveform $\left(\mathrm{A}_{2}-\mathrm{D}\right)$, a measure of the duration of isovolumic relaxation ${ }^{8}$; (b) duration of the early diastolic peak of flow velocity defined as the time interval from the onset of this peak to the time when flow velocity returned to baseline (D-F); (c) rate of decrease (deceleration) of flow velocity in early diastole (EF) calculated as the ratio $E-E^{\prime}$ to $E^{\prime}-F$; (d) maximal early diastolic flow velocity measured as the height of the early diastolic peak of flow velocity $(E)$; (e) maximal late diastolic flow velocity (which is due to atrial contraction) measured as the height of the late diastolic peak of flow velocity $(\mathrm{A}) ;(f)$ the ratio 


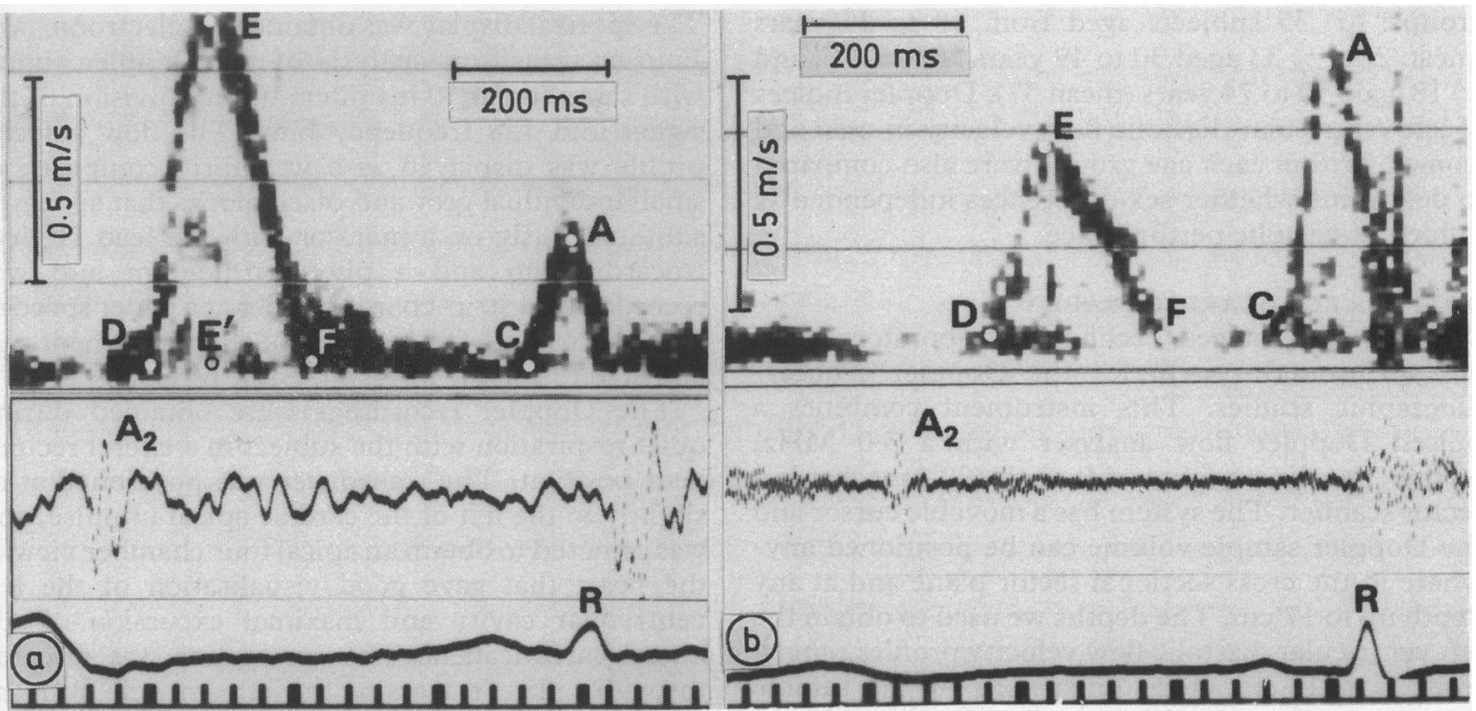

Fig 2 Doppler left ventricular diastolic flow velocity waveforms from two normal volunteers. (a) That of the younger subject (age 23 years) shows a shorter duration of isovolumic relaxation $\left(A_{2}-D\right)$ and rapid rate of decrease of flow velocity in early diastole $(E F)$; maximal early diastolic flow velocity $(E)$ is high relative to maximal late diastolic flow velocity $(A)$, giving an $E: A$ ratio of $>1$. (b) The waveform in the older subject (age 58 years) shows prolonged duration of isovolumic relaxation $\left(A_{2}-D\right)$ and reduced rate of decrease (descent) of flow velocity in early diastole (EF); maximal late diastolic (atrial) flow velocity $(A)$ is increased relative to maximal early diastolic flow velocity $(E)$, giving an $E: A$ ratio of $<1$.

between the maximal early and late diastolic flow velocities (E:A).

Because the flow velocity waveform is displayed as a grey scale line of variable thickness, the points $\mathrm{D}, \mathrm{E}$, and $A$ on the flow velocity contour were identified as the midpoints of the grey scale spectrum. The slope EF was defined by the construction of a straight line that passed through the midportion of the grey scale spectrum and corresponded to the descent of the early diastolic flow velocity peak. When the slope EF was curved rather than straight, EF was constructed as the line that identified the maximal incline of the slope. ${ }^{58}$ Because the contour of the flow velocity waveforms often shows a wide spectral spread at the end of the early flow velocity peak (point F on fig 2a), this point was identified as the intersection between the line of the descent of the early diastolic flow velocity peak and the baseline of the peak. ${ }^{58}$ At rapid heart rates (over about 90 beats/minute) the flow velocity curve does not return to baseline between the $E$ and $A$ peaks. In our subjects, however, the highest heart rate was 73 beats/minute; thus all flow velocity curves analysed as part of this study returned to baseline at point $F$.

Reproducibility of these Doppler diastolic indexes has been shown to be satisfactory with a relatively low intraobserver and interobserver variability. ${ }^{5}$

\section{STATISTICAL ANALYSIS}

Data were expressed as mean (2 SD). Relations between age and Doppler indices of left ventricular diastolic performance were assessed by linear regression analysis. Differences in Doppler diastolic indices between age groups were determined by the one way analysis of variance and those between sexes by the Student's unpaired $t$ test. To assess whether the effect of age on Doppler indices of diastolic function is independent of the influence of other variables, we used a multivariate linear regression analysis. ${ }^{12}$ Specifically, the influence of the following variables was assessed: ventricular septal and posterior left ventricular free wall thicknesses; left ventricular cavity dimensions at end diastole and end systole; percentage fractional shortening; and heart rate.

\section{Results}

RELATION BETWEEN AGE AND DOPPLER INDICES OF DIASTOLIC FUNCTION

Five of the six Doppler diastolic indices measured in the present study showed a linear relation with age (table 1). The duration of isovolumic relaxation and maximal late diastolic (atrial) flow velocity increased 
Table 1 Relation between Doppler indices of left ventricular diastolic function and age

\begin{tabular}{lcc}
\hline & $\begin{array}{l}\text { Correlation } \\
\text { coefficient } \\
(r)\end{array}$ & $\begin{array}{l}\text { Statistical } \\
\text { significance } \\
(p)\end{array}$ \\
\hline Doppler indices & 0.39 & $<0.001$ \\
\hline Isovolumic relaxation & 0.04 & $>0.05$ \\
Duration of early flow velocity & -0.40 & $<0.001$ \\
peak & -0.30 & $<0.005$ \\
Eeceleration of early flow velocity & 0.69 & $<0.001$ \\
Late maximal flow velocity & -0.63 & $<0.001$ \\
Ratio of early:late maximal flow & & \\
\hline velocities & & \\
\hline
\end{tabular}

with age (fig 3). Conversely, maximal early diastolic flow velocity, the rate of decrease (deceleration) of flow velocity in early diastole, and the ratio between the maximal early and late diastolic flow velocities decreased with age (fig 4). The duration of the early diastolic peak of flow velocity did not show a linear relation with age. Table 1 gives the values of the correlation coefficients of the regressions and their statistical significance.

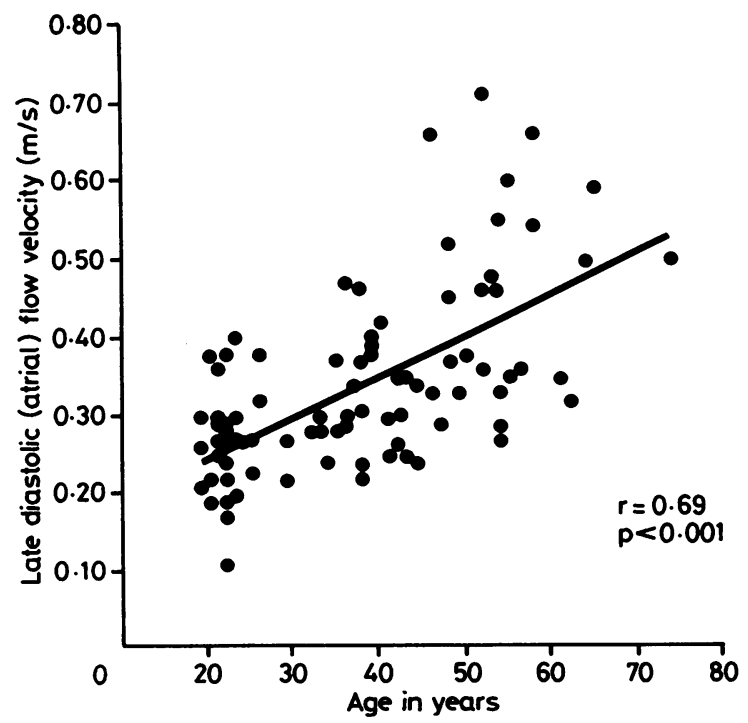

Fig 3 Relation between age and maximal late diastolic (atrial) flow velocity $(A)$.

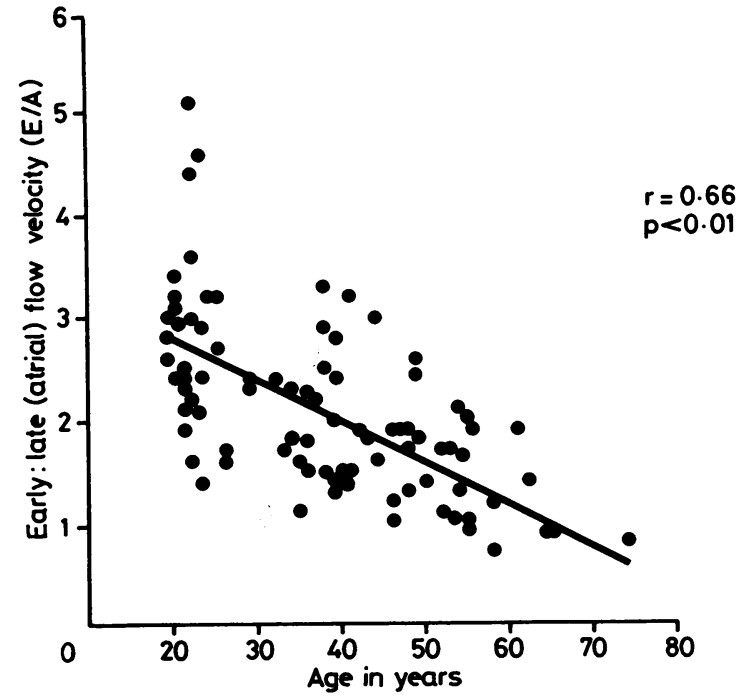

Fig 4 Relation between age and the ratio of maximal early diastolic to late diastolic (atrial) flow velocities ( $E: A$ ).

COMPARISON OF DOPPLER DIASTOLIC INDICES IN DIFFERENT AGE GROUPS

Several Doppler indices of left ventricular diastolic performance were significantly different in the three age groups (table 2 and fig 2). Isovolumic relaxation time was longer in the older subjects $(84(12) \mathrm{ms})$ than in the younger subjects $(72(12) \mathrm{ms} ; \mathrm{p}<0.001)$, and was also longer in the intermediate $(80(12) \mathrm{ms})$ age group than the younger age group ( $<<0.01$ ) (fig 5 ). Furthermore, the rate of decrease (deceleration) of flow velocity in early diastole was lower in the older subjects $\left(4 \cdot 2(1 \cdot 2) \mathrm{m} / \mathrm{s}^{2}\right)$ than in the younger subjects $\left(5.5(1.2) \mathrm{m} / \mathrm{s}^{2} ; \mathrm{p}<0.001\right)$, and it was also lower in the intermediate $\left(4.7(1.1) \mathrm{m} / \mathrm{s}^{2}\right)$ age group than the younger age group $(p<0.01$ ) (fig 6$)$. The ratio between the maximal early and late diastolic flow velocities was also lower in the older subjects $(1 \cdot 2$ $(0.4)$ than in either the intermediate $(2.0(0.6) ; \mathrm{p}<$ $0.002)$ or the younger subjects $(2.7(0.7) ; \mathrm{p}<0.001)$ (fig 7). A ratio of $<1$ was identified in five $(28 \%)$ of the 18 subjects who were 50 years of age or older, whereas this ratio was $>1$ in each of the 68 study

Table 2 Comparison of Doppler indices of diastolic function in three age groups

\begin{tabular}{|c|c|c|c|c|c|c|}
\hline $\begin{array}{l}\text { Age } \\
\text { (yr) }\end{array}$ & $\begin{array}{l}\text { Isovolumic } \\
\text { relaxation } \\
\text { (ms) }\end{array}$ & $\begin{array}{l}\text { Duration of } \\
\text { early flow } \\
\text { velocity peak } \\
\text { (ms) }\end{array}$ & $\begin{array}{l}\text { Deceleration } \\
\text { of early } \\
\text { flow velocity } \\
\left(\mathrm{m} / \mathrm{s}^{2}\right)\end{array}$ & $\begin{array}{l}\text { Early maximal } \\
\text { flow velocity } \\
(\mathrm{m} / \mathrm{s})\end{array}$ & $\begin{array}{l}\text { Late maximal } \\
\text { flow velocity } \\
(\mathrm{m} / \mathrm{s})\end{array}$ & $\begin{array}{l}\text { Early:late } \\
\text { maximal } \\
\text { flow velocities }\end{array}$ \\
\hline $\begin{array}{l}20-29 \\
30-49 \\
50-74\end{array}$ & $\begin{array}{l}72(12) \\
80(12)^{\star} \\
84(12) \dagger\end{array}$ & $\begin{array}{l}218(30) \\
220(27) \\
221(33)\end{array}$ & $\begin{array}{l}5 \cdot 5(1 \cdot 2) \\
4 \cdot 7(1 \cdot 1)^{\star} \\
4 \cdot 2(1 \cdot 2) \dagger\end{array}$ & $\begin{array}{l}0.69(0.12) \\
0.62(0.14) \\
0.59(0.14)\end{array}$ & $\begin{array}{l}0.27(0.07) \\
0.33(0.07) \\
0.46(0.13)\end{array}$ & $\begin{array}{l}2.7(0.7) \\
2 \cdot 0(0.6) \dagger \\
1 \cdot 2(0.4) \dagger t\end{array}$ \\
\hline
\end{tabular}

${ }^{\star} p<0.01$ compared with $20-29$ year old subjects; $\nmid p<0.001$ compared with $20-29$ year old subjects; $\ddagger p<0.002$ compared with $30-49$ year old subjects. 


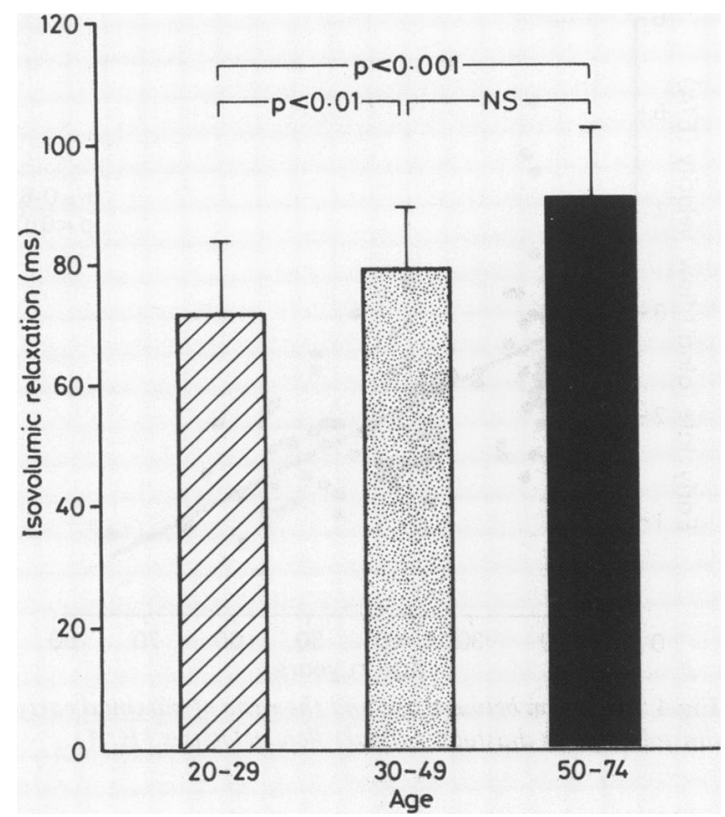

Fig 5 Comparison of duration of isovolumic relaxation $\left(A_{2}-D\right)$ in three age groups.

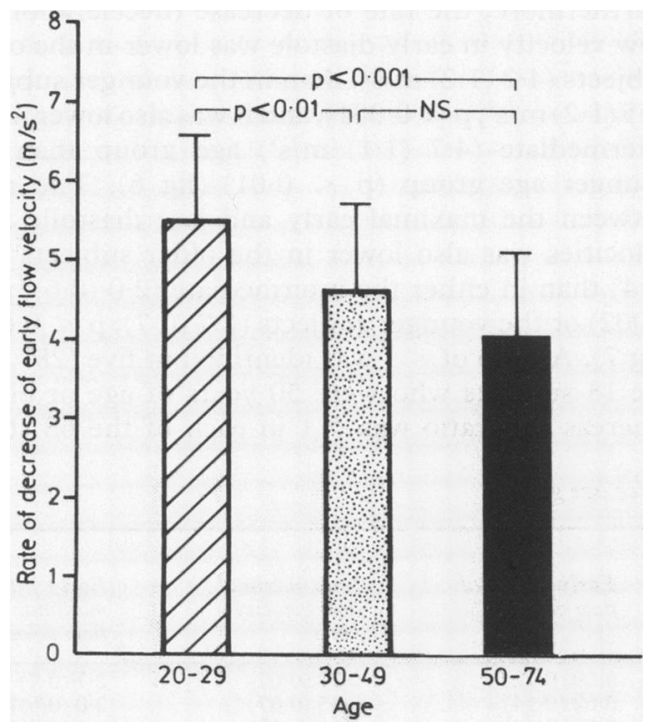

Fig 6 Comparison of the rate of decrease (deceleration) of flow velocity in early diastole (EF) in three age groups.

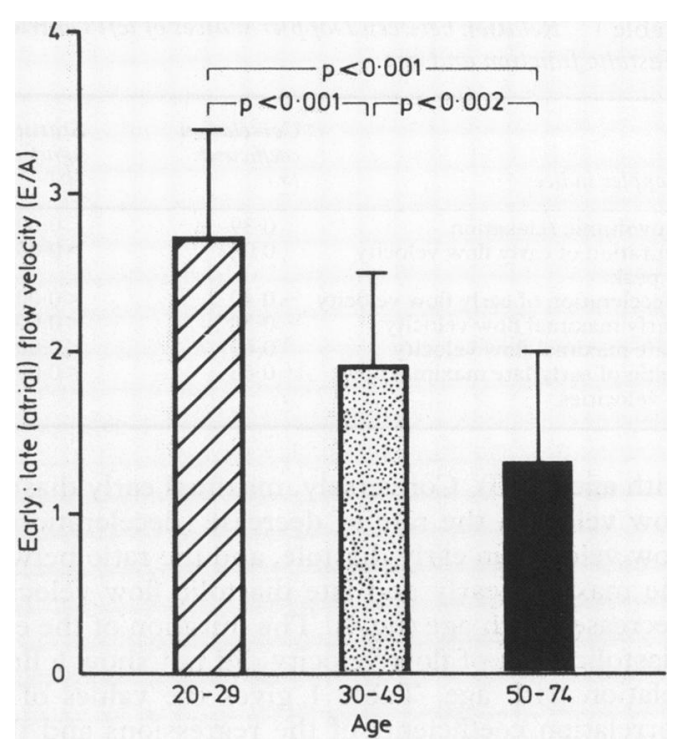

Fig 7 Comparison of the ratio between the maximal early and late diastolic (atrial) flow velocities ( $E: A)$ in three age groups.

subjects who were younger than 50 ( $p<0.001$ ). Heart rate was lower in the younger individuals $(56$ (7) beats/minute) than in the older ones (61 (6) beats/ minute; $p<0.02$ ). In the intermediate age group the heart rate $(59(6)$ beats/minute) was not significantly different from that of the other two groups.

No differences were identified between the sexes for Doppler diastolic indices, except for a shorter duration of the early flow velocity peak in women aged 20-29 (table 3).

MULTIVARIATE ANALYSIS

Multivariate linear regression analysis showed that age is an independent, strong determinant of most Doppler indices of left ventricular diastolic flow velocity. A significant correlation persisted between age and the duration of isovolumic relaxation, rate of decrease of flow velocity in early diastole, maximal late diastolic flow velocity, and the ratio between maximal early and late diastolic flow velocities after adjustment for left ventricular dimensions, percentage fractional shortening, and heart rate (table 4). Hence, as shown in table 4, these multivariate regression coefficients and the associated $p$ values did not differ from those of the univariate analysis. After adjustment for these independent variables, however, age no longer correlated significantly with maximal early diastolic flow velocity. 
Table 3 Comparison of Doppler indices of diastolic function in men and women

\begin{tabular}{|c|c|c|c|c|c|c|}
\hline Group & $\begin{array}{l}\text { Isovolumic } \\
\text { relaxation } \\
\text { (ms) }\end{array}$ & $\begin{array}{l}\text { Duration of } \\
\text { early flow } \\
\text { velocity peak } \\
\text { (ms) }\end{array}$ & $\begin{array}{l}\text { Deceleration } \\
\text { of early } \\
\text { flow velocity } \\
\left(\mathrm{m} / \mathrm{s}^{2}\right)\end{array}$ & $\begin{array}{l}\text { Early maximal } \\
\text { flow velocity } \\
(\mathrm{m} / \mathrm{s})\end{array}$ & $\begin{array}{l}\text { Late maximal } \\
\text { flow velocity } \\
(\mathrm{m} / \mathrm{s})\end{array}$ & $\begin{array}{l}\text { Early:late } \\
\text { maximal } \\
\text { flow velocities }\end{array}$ \\
\hline $\begin{array}{l}\text { Age 20-29: } \\
\text { Men } \\
\text { Women } \\
\text { Age 30-49: }\end{array}$ & $\begin{array}{l}71(10) \\
74(12)\end{array}$ & $\begin{array}{l}226(30)^{\star} \\
203(22)^{\star}\end{array}$ & $\begin{array}{l}5.4(1.2) \\
5.7(1.2)\end{array}$ & $\begin{array}{l}0.70(0.10) \\
0.66(0.12)\end{array}$ & $\begin{array}{l}0.26(0.06) \\
0.28(0.07)\end{array}$ & $\begin{array}{l}2.8(0.8) \\
2.6(0.9)\end{array}$ \\
\hline $\begin{array}{l}\text { Men } \\
\text { Women } \\
\text { Age 50-74: }\end{array}$ & $\begin{array}{l}82(11) \\
79(11)\end{array}$ & $\begin{array}{l}224(23) \\
217(31)\end{array}$ & $\begin{array}{l}4 \cdot 6(1 \cdot 2) \\
4 \cdot 8(1.4)\end{array}$ & $\begin{array}{l}0.59(0.14) \\
0.64(0.13)\end{array}$ & $\begin{array}{l}0.35(0.09) \\
0.32(0.05)\end{array}$ & $\begin{array}{l}1.8(0.6) \\
2.0(0.5)\end{array}$ \\
\hline $\begin{array}{l}\text { Men } \\
\text { Women }\end{array}$ & $\begin{array}{l}84(9) \\
84(19)\end{array}$ & $\begin{array}{l}217(36) \\
224(32)\end{array}$ & $\begin{array}{l}4 \cdot 2(1 \cdot 1) \\
4 \cdot 2(0 \cdot 8)\end{array}$ & $\begin{array}{l}0.55(0.14) \\
0.61(0.15)\end{array}$ & $\begin{array}{l}0.50(0.15) \\
0.49(0.12)\end{array}$ & $\begin{array}{l}1.1(0.2) \\
1.3(0.5)\end{array}$ \\
\hline
\end{tabular}

${ }^{\star} \mathrm{p}<0.025 ;$ no other comparisons in the table were statistically significant.

Table 4 Regression analyses of the relation between Doppler indices and age

\begin{tabular}{|c|c|c|c|c|c|c|}
\hline \multirow[b]{2}{*}{ Doppler indices } & \multicolumn{3}{|c|}{ Univariate analysis* } & \multicolumn{3}{|c|}{ Multivariate analysis $\dagger$} \\
\hline & $b$ & $S E$ & $p$ & $b$ & $S E$ & $p$ \\
\hline $\begin{array}{l}\text { Isovolumic relaxation } \\
\text { Duration early flow velocity peak } \\
\text { Deceleration early flow velocity } \\
\text { Early maximal flow velocity } \\
\text { Late maximal flow velocity } \\
\text { Early:late maximal flow velocities }\end{array}$ & $\begin{array}{l}0.35 \\
0.08 \\
-0.04 \\
-0.003 \\
0.006 \\
-0.04\end{array}$ & $\begin{array}{l}0.09 \\
0 \cdot 23 \\
0.01 \\
0.001 \\
0.001 \\
0.005\end{array}$ & $\begin{array}{l}<0.001 \\
>0.05 \\
<0.0001 \\
<0.005 \\
<0.0001 \\
<0.0001\end{array}$ & $\begin{array}{c}0.34 \\
0.35 \\
-0.04 \\
-0.002 \\
0.005 \\
-0.03\end{array}$ & $\begin{array}{l}0 \cdot 11 \\
0 \cdot 26 \\
0 \cdot 01 \\
0 \cdot 001 \\
0 \cdot 0007 \\
0.006\end{array}$ & $\begin{array}{l}<0.01 \\
>0.05 \\
<0.001 \\
>0.05 \\
<0.0001 \\
<0.0001\end{array}$ \\
\hline
\end{tabular}

*From the regression analysis to measure the effect of age on each of the dependent Doppler indices of diastolic function.

†From the multivariate linear regression analysis to measure the effect of the set of independent variables (age, ventricular septal and posterior free wall thickness, left ventricular cavity dimensions, percentage fractional shortening, and heart rate) on each of the dependent Doppler indices of diastolic function.

b, regression coefficient for age.

\section{Discussion}

The effects of aging on left ventricular diastolic performance have not been studied extensively in human beings, in part because it is difficult to obtain data from large numbers of healthy individuals by invasive techniques such as cardiac catheterisation. Nevertheless, haemodynamic data obtained in small numbers of people without heart disease have suggested that the normal left ventricle becomes stiffer and diastolic filling is altered with aging. ${ }^{13}$ Additional information on the influence of aging on diastolic performance has come from indirect, non-invasive measurements. Observations obtained from the mitral valve echogram have suggested that the rate of early left ventricular filling is reduced in healthy elderly people. ${ }^{14-17}$ More recently, data obtained from the Doppler diastolic flow velocity waveform also seem to indicate that the filling patterns of the left ventricle may be influenced by aging. ${ }^{17}$ In particular, the relative contribution of atrial systole to overall left ventricular filling seems to increase with age. ${ }^{17}$ In addition; a recent investigation by radionuclide angiography has shown a strong relation between age and peak filling rate. ${ }^{18}$

The findings of the present investigation of a large population of healthy volunteers confirm and extend these previous observations. In our study, age related changes were identified for five of the six of the Doppler indices of diastolic performance that were analysed. These alterations affected the isovolumic phase as well as the early and late filling phases of diastole. Aging was associated with an increased duration of isovolumic relaxation and a reduced rate of decrease of flow velocity in early diastole. In addition, maximal early diastolic flow velocity decreased and late diastolic flow velocity (largely owing to atrial systole) increased linearly with age; hence, the ratio between early and late diastolic flow velocity was significantly lower in older subjects. The enhanced flow velocity during atrial systole probably represents a compensatory mechanism for the reduced flow velocity during the early phase of diastole.

Alterations in the Doppler left ventricular diastolic waveform identified in our older subjects seemed to be qualitatively similar to, although not as severe as, those previously seen in patients with various cardiac diseases associated with diastolic impairment (including coronary artery disease, systemic hypertension, aortic valve stenosis, and hypertrophic cardiomyopathy. ${ }^{2356}$ Thus the results of our study are 
also relevant to the question of what should be considered to be a "normal" Doppler diastolic waveform. For example, if a large number of older people are included in a normal control population, then the range of values for the Doppler indices of left ventricular relaxation and filling will be increased, and this will reduce the sensitivity for detecting true abnormalities of diastolic performance. Similarly, because measures of diastolic function in older normal subjects may lie considerably outside the range seen in younger subjects, left ventricular diastolic impairment could be incorrectly identified in older individuals. These considerations suggest that values for Doppler indices of left ventricular diastolic performance measured in patients with cardiac disease should always be compared with those in age matched healthy controls.

Because coronary arteriography was not performed we cannot exclude unequivocally the possibility that some of our older subjects had clinically silent coronary artery disease. But coronary arteriography is unjustified and impractical in a healthy symptom free population such as ours. The changes in the Doppler diastolic waveform that we identified in the older volunteers were pronounced and consistent, however, and the occasional individual with silent coronary disease would not account for important differences in the pattern of flow velocity that we identified in the younger and older volunteers.

Left ventricular diastolic filling is a complex phenomenon influenced not only by the intrinsic properties of the cardiac muscle, but also by variables such as left ventricular mass and volume, systolic function, heart rate, and the loading conditions of the ventricle. ${ }^{19-26}$ Since Doppler diastolic indices may be influenced by these multiple variables, the alterations in the diastolic waveform identified in our older study subjects do not definitively demonstrate that aging, per se, alters the primary intrinsic properties of the cardiac muscle (that is left ventricular relaxation and elastic properties of the ventricle). Data derived from our multivariate regression analysis do, however, support this hypothesis. For example, the multivariate linear regression analysis showed that age correlated significantly with most Doppler indices of left ventricular diastolic function, even after adjustment for left ventricular wall thickness and cavity dimension, percentage systolic shortening, or cycle length. Thus these data indicate that the effects of age on Doppler diastolic indices are independent of age related alterations in left ventricular morphology and function. Although all our study subjects had normal systemic blood pressure, left ventricular afterload was not measured directly. Thus a slight increase in left ventricular systolic load caused by reduced arterial wall distensibility ${ }^{26}$ may have influenced transmitral flow velocity in our older subjects. Nevertheless, slight changes in systolic load do not seem to be sufficient to explain the size of the alterations in the left ventricular flow velocity waveform that we identified in older individuals.

In conclusion, our findings indicate that the Doppler left ventricular diastolic waveform is altered substantially by aging, and that age is an independent determinant of most indexes of left ventricular diastolic flow velocity. Thus the effects of age should be considered when the normal limits for Doppler indices of left ventricular diastolic function are defined.

We thank Dr Joel Verter for helpful statistical assistance and Judith $\mathrm{S}$ Merrill for technical assistance.

\section{References}

1 Miyatake K, Okamoto M, Kinoshita N, et al. Augmentation of atrial contribution to left ventricular inflow with aging as assessed by intracardiac Doppler flowmetry. Am J Cardiol 1984;53:586-9.

2 Fujii J, Yoshizumi Y, Sawada H, Aizawa T, Watanabe $H$, Kato K. Noninvasive assessment of left and right ventricular filling in myocardial infarction with a two-dimensional Doppler echocardiographic method. J Am Coll Cardiol 1985;5:1155-60.

3 Snider RA, Gidding SS, Rocchini AP, et al. Doppler evaluation of left ventricular diastolic filling in children with systemic hypertension. Am J Cardiol 1985;56:921-6.

4 Rokey R, Kuo LC, Zoghbi WA, Limacher MC, Quinones MA. Determination of parameters of left ventricular diastolic filling with pulsed Doppler echocardiography: comparison with cineangiography. Circulation 1985;71:543-50.

5 Spirito P, Maron BJ, Bonow RO. Noninvasive assessment of left ventricular diastolic function: comparative analysis of Doppler echocardiographic and radionuclide angiographic techniques. $\mathrm{J} \mathrm{Am}$ Coll Cardiol 1986;7:518-26.

6 Takenaka K, Dabestani A, Gardin JM, et al. Left ventricular filling in hypertrophic cardiomyopathy: a pulsed Doppler echocardiographic study. J Am Coll Cardiol 1986;7:1263-71.

7 Gardin JM, Rohan MK, Davidson DM, et al. Doppler transmitral flow velocity parameters: relationship between age, body surface area, blood pressure and gender in normal subjects. Am J Noninv Cardiol 1986;1:3-10.

8 Spirito P, Maron BJ, Bellotti P, Chiarella F, Vecchio C. Noninvasive assessment of left ventricular diastolic function: comparative analysis of pulsed Doppler ultrasound and digitized $\mathrm{M}$-mode echocardiography. Am J Cardiol 1986;58:837-43.

9 Louie EK, Rich S, Brundage BH. Doppler echocardiographic assessment of impaired left ventricular 
filling in patients with right ventricular pressure overload due to primary pulmonary hypertension. $J$ Am Coll Cardiol 1986;8:1298-306.

10 Friedman BJ, Drinkovic N, Miles H, Shih W, Mazzoleni A, De Maria AN. Assessment of left ventricular diastolic function: comparison of Doppler echocardiography and gated blood pool scintigraphy. J Am Coll Cardiol 1986;8:1348-54.

11 Bryg RJ, Williams GA, Labovitz AJ. Effect of aging on left ventricular diastolic filling in normal subjects. $\mathrm{Am}$ J Cardiol 1987;59:971-4.

12 Draper NR, Smith H. Applied regression analysis. New York: Wiley and Sons, 1966.

13 Hirota Y. A clinical study of left ventricular relaxation. Circulation 1980;62:756-63.

14 Derman U. Changes of the mitral echocardiogram with aging and the influence of the atherosclerotic risk factors. Atherosclerosis 1972;15:349-57.

15 Luisada AA, Watanabe $\mathrm{K}$, Bhat PK, Rao DB. Correlates of the echocardiographic waves of the mitral valve in normal subjects of various ages. $\mathrm{J} \mathrm{Am}$ Geriatr Soc 1975;23:216-23.

16 Gerstenblith G, Frederiksen J, Yin FCP, Fourtuin NJ, Lakatta EG, Weisfeldt ML. Echocardiographic assessment of a normal adult aging population. Circulation 1977;56:273-8.

17 Gardin JM, Henry WL, Savage DD, Ware JH, Burn C, Borer JS. Echocardiographic measurements in normal subjects: evaluation of an adult population without clinically apparent heart disease. JCU 1979; 7:439-47.

18 Miller TR, Grossman SJ, Schectman KB, Biello DR, Ludbrook PA, Ehsani AA. Left ventricular diastolic filling and its association with age. Am J Cardiol 1986;58:531-5.

19 Gaasch WH, Cole JS, Quinones MA, Alexander JK. Dynamic determinants of left ventricular diastolic pressure-volume relations in man. Circulation 1975;51:317-23.

20 Grossman W, McLaurin LP. Diastolic properties of the left ventricle. Ann Intern Med 1976;84:316-26.

21 Upton MT, Gibson DG, Brown DJ. Echocardiographic assessment of abnormal left ventricular relaxation in man. Br Heart $J$ 1976;38:1001-9.

22 Glantz S, Parmley W. Factors which affect the diastolic pressure-volume curve. Circ Res 1978;72:171-80.

23 Frederiksen JW, Weiss JL, Weisfeldt ML. Time constant of isovolumic pressure fall: determinants in the working left ventricle. Am J Physiol 1978;235: H701-6.

24 Carroll JD, Hess OM, Hirzel HO, Krayenbuehl HP. Dynamics of left ventricular filling at rest and during exercise. Circulation 1983;68:59-67.

25 Brutsaert DL, Rademakers FE, Sys SU. Triple control of relaxation: implications in cardiac disease. Circulation 1984;69:190-6.

26 O'Rourke MF, Yaginuma T. Wave reflections and the arterial pulse. Arch Intern Med 1984;144:366-71. 